\title{
Re-examining How Partner Co-presence and Multitasking Affect Parents' Enjoyment of Childcare and Housework
}

\author{
Allison Dunatchik, ${ }^{a}$ Svetlana Speight ${ }^{\mathrm{b}}$ \\ a) The University of Pennsylvania; b) The National Centre for Social Research
}

\begin{abstract}
Partner co-presence and multitasking are two contextual characteristics of time use that are commonly theorized to affect parental well-being. Although partner co-presence is often assumed to promote greater well-being, multitasking is frequently conceptualized as an indicator of time pressure. This study re-examines the relationship between these contextual characteristics and parents' enjoyment of childcare and housework. Using data from the U.K. Time Use Survey (2014-2015), our results indicate that associations between partner co-presence, multitasking, and enjoyment of unpaid work vary substantively depending on the type of task carried out. They also vary by gender of the parent. Mothers reported greater enjoyment of housework and interactive childcare with a partner present; however, this association did not extend to other types of childcare. Fathers' enjoyment varied little by partner co-presence. Similarly, multitasking was a varied experience depending on the types of activities parents combined. In some instances, combining unpaid work activities (e.g., housework with childcare) was associated with lower enjoyment; however, combining unpaid work with leisure was often associated with greater enjoyment. These results add nuance to prior research on how the contextual characteristics of time use relate to parental well-being and suggest that prior conceptualizations of partner co-presence and multitasking are incomplete.
\end{abstract}

Keywords: parenthood; well-being; time use; families and work; gender and families

Citation: Dunatchik, Allison, and Svetlana Speight. 2020. "Re-examining How Partner Copresence and Multitasking Affect Parents' Enjoyment of Childcare and Housework." Sociological Science 7: 268-290.

Received: March 1, 2020

Accepted: May 24, 2020

Published: July 28, 2020

Editor(s): Jesper Sørensen, Mario Small

DOI: $10.15195 /$ v7.a11

Copyright: (C) 2020 The Author(s). This open-access article has been published under a Creative Commons Attribution License, which allows unrestricted use, distribution and reproduction, in any form, as long as the original author and source have been credited. (C) (i)

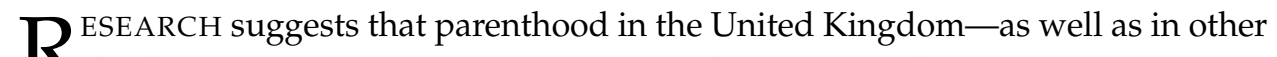
high income countries-is an increasingly pressurized experience, stemming from a cultural shift towards time-intensive, child-centered parenting (Hays 1996; O'Brien et al. 2015) as well as the increasing prevalence of full-time working mothers (Connolly et al. 2016; Office for National Statistics 2018). In the United Kingdom, recent evidence suggests that, after taking sociodemographics into account, U.K. parents are around 8 percent less happy than their nonparent counterparts (Glass, Simon, and Andersson 2016). Theories of stress and well-being (e.g., Pearlin 1989) provide a useful framework for conceptualizing parental well-being, suggesting that parenthood exposes individuals to a variety of stressors that may negatively influence well-being, such as increased demands on time, energy and finances, additional work-family conflict, and greater role strain. However, the impact that exposure to stressors has on parents' well-being is mediated by factors including the extent to which parents have access to social support and the coping strategies they employ.

A growing body of empirical research has sought to understand the relationship between parents' time use patterns and their subjective well-being on a moment-tomoment basis (such as stress, happiness, sadness) and to examine what aspects of 
parenting may be particularly associated with greater or lower well-being. These studies have tended to focus exclusively on parents' childcare time and time with children (e.g., Meier et al. 2018; Musick, Meier, and Flood 2016; Roeters and Gracia 2016). However, parenting responsibilities extend beyond the time parents spend directly with their children, with parenthood increasing the burden of other domestic responsibilities like cooking, cleaning, clothes care, and shopping (e.g., Craig 2006a) in addition to direct childcare time. This suggests that analysis of parents' experience of housework as well as childcare is needed to gain a better understanding of how parents experience their parenting responsibilities.

Empirical investigations of parents' moment-to-moment well-being in the U.S. context have generally found that parents report greater enjoyment and meaning in time spent with their children (Musick et al. 2016; Offer 2014; Offer and Schneider 2011). However, studies have also found that parents' moment-to-moment wellbeing varies by factors such as gender, the age of children, and the type of activity carried out as well as contextual characteristics of time use (Mattingly and Sayer 2006; Offer 2014; Offer and Schneider 2011; Roeters and Gracia 2016).

Two contextual factors of time use that have garnered particular attention for their potential to affect parents' experience of their time spent on childcare and housework include whether a partner is present during the activity and whether parents are multitasking at the time. Research suggests that shared time within couples is important for marital well-being (e.g., Hill 1988; White 1983; Zuo 1992) and that, in general, couples report greater happiness when spending time together (Flood and Genadek 2016). Partner co-presence is therefore often assumed to be indicator of bonding and social support, which suggests a positive association between partner co-presence and parental well-being. However, the empirical literature is mixed on the extent to which having a spouse or partner present during unpaid work activities is associated with enjoyment. Some studies identify a positive association between partner presence and enjoyment of housework and childcare for mothers but not for fathers (Sullivan 1996b, 1996a), whereas other studies find a positive association for fathers' well-being only (Roeters and Gracia 2016), and others find no association at all (McDonnell, Luke, and Short 2019). Meanwhile, multitasking is often conceptualized as a strategy individuals use to cope with excessive demands on their time and is often assumed to be a negative experience. However, empirical evidence again is divided on the implications of multitasking for well-being, with some studies identifying a negative association (Craig and Brown 2017; Offer and Schneider 2011) and others finding no association (Sullivan and Gershuny 2018).

A key limitation of most existing research on parental well-being and partner presence and multitasking is that few studies consider whether these associations vary depending on the types of activities carried out. Research on couples' time coordination and enjoyment of activities has found that women's enjoyment of traditionally female-typed housework tasks in particular (such as cleaning and clothes care) benefits from performing these tasks alongside a partner, with the idea that male partners in these instances are "helping out" with what are primarily their partners' responsibilities (Sullivan 1996a, 1996b). Therefore, it follows that 
parents' experience of partner co-presence may vary depending on the type of activity carried out and who takes primary responsibility for that task.

Similarly, previous investigations on the link between multitasking and parental well-being (e.g., Offer and Schneider 2011) have often overlooked the possibility that the experience of multitasking is likely to differ depending on the types of activities that are paired together and whether parents are combining housework and childcare tasks with a leisure activity or another unpaid work task. Furthermore, the relationship between multitasking and parents' moment-to-moment well-being has been largely ignored in recent empirical literature, owing to the fact that the majority of recent studies draw on the well-being module of the American Time Use Survey (ATUS), which only collects secondary activity information for episodes when a respondent reports that a children aged 13 or younger is in their care and therefore precludes comprehensive analysis of multitasking.

This article seeks to reconcile conflicting results in prior empirical studies by re-examining the associations between partner co-presence and multitasking and parental well-being, taking into account the types of activities carried out. Using data from the most recent wave of the U.K. Time Use Survey (UKTUS) from 2014 to 2015 (Gershuny and Sullivan 2017), we find that the relationship between partner copresence and multitasking and enjoyment of housework and childcare tasks differs depending on the tasks carried out and that often these patterns vary by gender. For partner presence, we find that mothers enjoyed housework and interactive childcare more with a partner present but that the same pattern was not true for more routine childcare tasks. Meanwhile, fathers' enjoyment of housework and childcare varied little by partner co-presence. For multitasking we found that combining childcare and housework tasks with leisure activities was often associated with greater enjoyment, whereas combining multiple unpaid work tasks was not always associated with lower enjoyment and in some instances was actually rated as more enjoyable than unpaid work that was single-tasked. These results add nuance to prior research on the relationship between contextual characteristics of housework and childcare time and parental well-being and suggest that prior conceptualizations of partner presence as support and multitasking as time pressure are incomplete.

\section{Background}

\section{Parental Well-Being and the Process of Stress}

Theories around stress and well-being suggest that the well-being gap between parents and nonparents stems from the fact that parenthood exposes individuals to a variety of stressors relating to the parenting role (Nomaguchi and Milkie 2017; Pearlin 1989). These include parenthood-related strains like role overload, where the demands of parenting exceed individuals' capacity; inter-role conflict, where the role of parenting conflicts with other roles (e.g., worker) embodied by an individual; and role captivity, where parents may feel trapped by the responsibilities associated with parenthood (Pearlin 1989, 1999). 
Parents experience and react to these stressors in heterogeneous ways, and exposure to similar stressors may manifest differently in well-being outcomes across individuals. As Pearlin (1989) argued, one reason for these differences is heterogeneity in mediating factors like coping-the actions that individuals take or the resources they possess and deploy to avoid or reduce the impact of stressorsand social support-the relationships and social networks that individuals may rely on for help in dealing with life's problems. This article investigates the relationship between two such possible mediating factors, multitasking and partner presence, and parents' well-being during childcare and housework activities.

\section{Measuring Parental Well-Being}

Much of the existing literature on parental well-being has focused on global measures of well-being, analyzing the relationship between parenthood and broad self-assessments of happiness, overall life satisfaction, and feeling that things in life are worthwhile. However, the inclusion of a variety of subjective well-being measures in a number of national time diary survey instruments in recent years has enabled the development of a growing body of literature that investigates parental well-being on a moment-to-moment basis. These moment-to-moment measures of well-being relate to respondents' affect in particular moments in time or during particular activities (Kahneman, Diener, and Schwarz 1999).

Empirical studies have found that global and moment-to-moment measures of well-being tend to be associated (e.g., Lee et al. 2016) but only modestly so (e.g., Luhmann, Schimmack, and Eid 2011; Stone and Mackie 2013). Some theoretical perspectives have argued that moment-to-moment measures of well-being have a number of advantages over global measures. For example, Kahneman and Kreuger (2006) argued that moment-to-moment measures of well-being minimize the effects of the so-called "filter of memory," as well as of social desirability bias, and therefore may more accurately reflect an individual's subjective well-being compared with retrospective or global measures.

However, moment-to-moment measures of well-being are also conceptually distinct from global measures. As described by Stone and Mackie (2013:31), momentto-moment measures "are designed to capture emotions as they fluctuate from moment-to-moment and in response to day-to-day events and activities... [and] therefore aim to be reactive to a respondents' immediate focus." These measures may capture a different domain of well-being compared with more global measures such as life satisfaction, which reflect people's abstract evaluations of their current situation measured against their own values and expectations. This conceptual distinction suggests that global and moment-to-moment measures of well-being may be useful in answering different types of questions. In the context of measuring parental well-being, although global measures may be useful for addressing questions about how parenthood changes one's evaluation of life in general, moment-tomoment measures are better suited for assessing how parents experience particular moments, activities, or situations throughout the day.

Enjoyment of activities collected in time diary data constitutes one measure of moment-to-moment well-being, offering a measure of the "process benefits" (Dow 
and Juster 1985) or "instant utility" that individuals derive from the activities they carry out (Kahneman et al. 1999). Validation studies have shown that measures of enjoyment correspond well with other measures of moment-to-moment wellbeing like stress, fatigue, pain, happiness, and sadness. Comparing a five-item average of the moment-to-moment well-being measures available in the American Time Use Survey with a measure of enjoyment collected in earlier U.S. time diary studies, Robinson (2013) found that subjective well-being measured in ATUS largely replicated enjoyment ratings from previous surveys.

\section{Childcare, Housework, and Moment-to-Moment Well-Being}

Prior analysis of enjoyment in the United States and the United Kingdom has found that individuals' moment-to-moment well-being varies substantially by the types of activities they carry out (Gershuny 2013; Sullivan 1996a; Musick et al. 2016; Offer 2014). For example, individuals tend to report greater enjoyment during leisure and childcare activities and while socializing, and they report lower enjoyment during paid work and housework (Gershuny 2013; Gershuny and Sullivan 2019). However, research has also identified variation in moment-to-moment well-being even within categories of tasks. For both housework and childcare activities, individuals tend to report lower well-being during time-bound, routine, traditionally female-typed activities (such as cooking, cleaning, and clothes care for housework and feeding, bathing, and dressing children for childcare) than they do for other less routine types of housework and childcare activities (Gershuny and Sullivan 2019; McDonnell et al. 2019; Offer 2014; Sullivan 1996a).

\section{Partner Co-presence}

Parents' relationships and the extent to which they have access to social support are factors that likely influence parental experiences of housework and childcare activities. One indicator of parents' support may be the co-presence of a spouse or partner during childcare or domestic work. Prior research has suggested that spousal co-presence during childcare may serve as a source of both emotional and instrumental support, making tasks less demanding and allowing parents to interact and share the workload (Roeters and Gracia 2016; Roeters and Treas 2011). In this way, partner co-presence may serve as a mediating factor, reducing the negative effects of exposure to stressors and making tasks more enjoyable than they would otherwise be.

However, partner co-presence has also been shown to have important gendered dimensions and implications. Analyzing the proportion of individuals' childcare and housework time that was spent in coordination with one's partner versus on one's own, Sullivan (1997), using U.K. data, and Craig (2006b), using Australian data, found that fathers spent a substantially greater proportion of their unpaid work time alongside their female partners, whereas women were much more likely to do these tasks on their own. These results suggest that although men may undertake some unpaid work, the primary responsibility for these tasks lies with women, who serve a managerial role in planning and delegating unpaid work. These dynamics have implications for how parents experience tasks shared with a 
partner. Using U.K. data, Sullivan (1996b, 1996a) found that women in heterosexual couples enjoyed routine, female-typed housework tasks (including cleaning and clothes care) and childcare more when these activities were coordinated with their partners but that the same was not true for men, lending support to the notion that men's contributions to unpaid work may be done at women's prompting.

Curiously, these results for childcare are not replicated in more recent research on parents' momentary affective well-being during childcare time in the U.S. context. Roeters and Gracia (2016) found that a spouse's presence during childcare time was associated with lower stress levels and a greater sense of meaning but that these differences were modest and exclusive to fathers. Meanwhile, McDonnell et al. (2019) found that partner presence did not have a statistically significant impact on happiness, stress, tiredness, or meaning during childcare for either mothers or fathers. A key limitation of these studies, however, is that they do not consider whether the role of partner presence differs by the type of childcare activity carried out. Relative to fathers, mothers tend to carry out more of the routine, time-inflexible aspects of childcare (Raley, Bianchi, and Wang 2012; Sayer, Bianchi, and Robinson 2004). It is possible that, as Sullivan (Sullivan 1996b, 1996a) found for housework, partner co-presence during these childcare tasks in particular may be associated with greater enjoyment among mothers.

Drawing on these prior studies, we address two research questions in this article:

1. Does partner presence serve as a mediating factor, making childcare and housework tasks more enjoyable than they are in the absence of a partner?

2. Does this differ by gender and by type of activity carried out? Specifically, is partner presence associated with greater enjoyment particularly for traditionally female-typed tasks like core housework and routine childcare where gender gaps in time allocation are greatest?

\section{Multitasking}

Sociological and popular conceptualizations often frame multitasking as a strategy that individuals use to deal with excessive demands on their time. Describing multitasking as a measure of "time-deepening," Bianchi, Robinson, and Milkie (2006:98) argued that parents "try to gain time in their 24-hour days by multitasking-doing more activities at once to fit everything into their lives." Existing literature has consistently found that women are more likely than men to multitask, particularly when carrying out childcare or housework tasks (Offer and Schneider 2011; Sullivan 1997; Sullivan and Gershuny 2013, 2018). But a key tension in the literature is whether women's greater propensity to multitask unpaid work tasks stems from women's overall greater burden of unpaid work and subsequent time scarcity or whether it is simply a function of women's greater time spent at home and the compatibility of housework and childcare tasks (Sayer 2007; Sullivan and Gershuny 2013). From the first perspective multitasking may signal role overload or role conflict, whereas from the second perspective multitasking may simply reflect the nature of housework and childcare tasks, which may facilitate the combination of multiple tasks at the same time. 
Research has sought to resolve this tension by studying the relationship between multitasking and subjective measures of time pressure and well-being, but the empirical evidence remains mixed. Using U.K. data, Sullivan and Gershuny (2018) found that the proportion of the waking day spent multitasking was not significantly associated with feeling rushed either for men or for women, after controlling for time spent in paid and unpaid work and sociodemographic characteristics. Meanwhile, Craig and Brown (2017), using data from Australia, found that multitasking multiple unpaid work tasks was associated with greater time pressure among mothers, whereas multitasking leisure time was unrelated to feelings of rushedness.

One potential reason for the lack of consensus is that these studies consider the association between multitasking and feelings of rushedness at the individual level and do not examine how multitasking is experienced in the particular moments it occurs. One exception is a study by Offer and Schneider (2011), who, using data collected via the experience sampling method, found that multitasking was associated with increased stress and negative affect, particularly for mothers. However, an important limitation to their study and its generalizability is that their sample was composed of relatively affluent dual-earner couples. These findings have yet to be replicated in nationally representative data, owing partly to the fact that the American Time Use Study, which is commonly used to analyze parental time use and well-being, only collects secondary activity information when respondents indicate they are with a child aged 13 or younger. Another limitation is that Offer and Schneider (2011) did not take into consideration what types of activities are paired together when they are multitasked, which is likely an important determinant of how parents experience the act of multitasking. Considering individual-level rather than episode-level outcomes, for example, Craig and Brown (2017) found that time spent multitasking unpaid work tasks contributed to feelings of being rushed, whereas time spent multitasking leisure tasks did not. Furthermore, recent evidence suggests the extent to which individuals feel they have control of the activities they carry out when multitasking is strongly associated with how multitasking is experienced (Bachmann, Grunschel, and Fries 2019).

Building on these studies, we investigate two further research questions:

3. Does the relationship between parents' enjoyment and multitasking vary depending on the types of activities that are paired together? In particular, does enjoyment of a secondary leisure activity improve enjoyment of a less liked primary activity? Is combining two unpaid work activities more or less enjoyable than doing one unpaid work activity at a time?

4. Does the relationship between enjoyment and multitasking differ by gender of the parent?

\section{Data and Sample}

We use nationally representative data from the most recent wave of the UKTUS from 2014 to 2015 (Gershuny and Sullivan 2017), which contains a sample of more than 2,000 parents with a child aged 16 or younger in the household. UKTUS is a large-scale household survey consisting of a household interview, individual 
interviews, and two self-completion paper time diaries (covering one randomly allocated weekday and one randomly allocated weekend day) for all household members aged eight and older. The diary instrument consists of rows for each 10-minute period of the day, with separate columns where respondents record their main activity during each time period, any secondary activities carried out, location information, and co-presence of other individuals. Unlike earlier waves of data, the 2014-to-2015 diary instrument also contains a column recording respondents' enjoyment of their current activity for a random selection of respondents.

This episode-level indicator of respondents' activity enjoyment is our outcome of interest, providing a measure of the "process benefits" (Dow and Juster 1985) respondents derive from their current activity. Enjoyment is scored on a scale from 1 (not at all enjoyable) to 7 (very enjoyable) and is treated as a cardinal variable in this analysis. Fourteen percent of parents were not asked to record activity enjoyment and were therefore not included in this analysis. Reflecting the focus of this analysis on parents' enjoyment of childcare and housework time, we limited our sample to episodes where parents' primary activity was either a housework or childcare task. ${ }^{1}$ Finally, among respondents asked to record enjoyment, this information was missing for 11 percent of housework and childcare episodes, which were subsequently excluded from our sample.

Our final analytic sample consisted of 35,789 episodes, nested within 3,006 diary days collected from 1,558 parents. Table 1 presents sociodemographic and family characteristics of parents in our analytic sample, disaggregated by sex. Our sample was composed of 58 percent mothers and 42 percent fathers, reflecting the fact that our sample is limited to parents living together with their dependent children, and the proportion of female lone-parent households far exceeds that of male loneparent households. Furthermore, because mothers spend more time on average on childcare and housework and consequently have more episodes of childcare and housework activities per day than fathers do, 72 percent of total episodes in our sample were from mothers and 28 percent were from fathers.

Mothers in our sample were more likely than fathers to have a college degree (37 percent vs. 32 percent, respectively), whereas fathers were more likely than mothers to be employed ( 94 percent of fathers vs. 78 percent of mothers). Among parents currently or ever employed, 42 percent of mothers and 40 percent of fathers were employed in professional occupations. Mothers were younger than fathers on average (39 vs. 41 years) and were less likely to be married or cohabitating with a partner (82 percent vs. 96 percent). Parents had fewer than two children on average, and around 44 percent of parents had a child younger than five years old in the household.

\section{Methods}

To account for the multilevel nature of our data, we used two-level random intercept models with robust standard errors where activities (level 1) were nested within individuals (level 2). To explore the factors associated with parental enjoyment of 
Table 1: Descriptive characteristics of sample parents.

\begin{tabular}{lcc}
\hline & Mothers & Fathers \\
\hline College degree, \% & $36.8^{*}$ & 31.6 \\
Employed (including self-employed), \% & $78.2^{*}$ & 93.5 \\
Occupational class, \% & & \\
$\quad$ Professional & 42.1 & 40.2 \\
$\quad$ Intermediate & 27.1 & 29.8 \\
Routine & 30.9 & 30.1 \\
Married/cohabitating & $81.5^{*}$ & 96.4 \\
Number of children, mean (standard deviation) & 1.7 & 1.8 \\
& $(0.8)$ & $(0.8)$ \\
Children aged less than five years in the household, \% & 43.4 & 46.8 \\
Age, mean (standard deviation) & $38.8^{*}$ & 41.0 \\
& $(8.1)$ & $(8.2)$ \\
Number of individuals & 900 & 658 \\
Number of diary days & 1768 & 1238 \\
Number of episodes & 25,651 & 10,138 \\
\hline Note: ${ }^{\circ}<0.05:$ Moth
\end{tabular}

Note: ${ }^{*} p<0.05$ : Mothers' characteristics differ significantly from fathers'.

housework and childcare time, we used a base model (model 1), specified as

$$
\text { Enjoyment }_{e i}=\beta_{00}+\beta_{1} \gamma_{e i}+\beta_{2} \chi_{e i}+\beta_{3} \lambda_{e i}+\beta_{4} \psi_{e i}+\beta_{5} \rho_{0 i}+\beta_{6} \varphi_{0 i}+v_{0 i}+\varepsilon_{e i}
$$

for episode $e$ and individual $i$, where $v_{0 i}$ is a person-level random error term. $\gamma_{e i}$, $\chi_{e i}$, and $\lambda_{e i}$ represent our three main independent variables of interest. $\gamma_{e i}$ is an episode-level categorical variable indicating what type of housework or childcare activity was carried out as the primary activity in a particular episode. Categories include

- core housework (cooking, cleaning, and clothes care),

- nonroutine housework (including shopping, gardening, and household management),

- physical childcare (feeding, bathing, and dressing),

- interactive childcare (talking, reading, playing games with children), and

- other childcare (composed of child-related travel, supervisory childcare, and unspecified childcare).

$\chi_{e i}$ is a binary episode-level measure indicating whether a partner was present during a particular episode. Finally, $\lambda_{e i}$ is an episode-level categorical variable indicating whether the primary activity in an episode was carried out as a single activity or whether it was multitasked with a secondary activity. The measure distinguishes between single-tasked activities and those that were multitasked with housework as the secondary activity, with childcare as the secondary activity, with leisure as the secondary activity, and with other activities as the secondary activity. 
In addition to our main independent variables of interest, model 1 includes a number of control variables. $\psi_{e i}$ represents a vector of episode-level control variables including episode duration, duration squared, and the time of day the episode took place. $\rho_{0 i}$ represents a series of day-level control variables including daily time spent (in hours) on paid work, on leisure activities, and on sleep as well as whether the episode took place on a weekday or weekend day. Finally, $\varphi_{0 i}$ is a vector of individual-level sociodemographic and household variables. These include age (centered at the sample mean, 39.8), age squared, educational attainment (measured as a binary variable indicating whether an individual has a college degree), occupational class, partner status (measured as a binary indicator of whether an individual is single or married, civil partnered, or cohabiting with a partner), number of children, and a binary indicator of whether the respondent has a child younger than five years old in the household.

To explore the role of partner co-presence and multitasking in moderating or exacerbating how parents feel during housework and childcare time, we extended our base model (model 1) in two further models:

Model 2 analyzes whether partner presence improves or deteriorates parental enjoyment of childcare and domestic tasks. It includes interactions between our activity type variables and an episode-level binary variable indicating whether the activity was carried out in the presence of a partner.

Model 3 explores whether multitasking influences parental enjoyment of housework and childcare activities. It includes interactions between activity type variables and an episode-level five-category variable indicating whether the primary activity was carried out as a single activity or whether it was multitasked with housework, childcare, leisure, or other activities as the secondary activity.

Models 1 through 3 were initially run separately for mothers and fathers, then run on a pooled sample of mothers and fathers with gender interactions for all variables to assess whether gender differences were statistically significant. Supplementary Table 1 in the online supplement provides descriptive statistics for all individual-level, day-level, and episode-level variables included in our model, separated by gender.

\section{Results}

Descriptive patterns of parents' average enjoyment of and time allocations to housework and childcare tasks, presented in Table 2, show that although daily time allocations to housework and childcare tasks varied considerably between mothers and fathers-with mothers performing substantially more housework and childcare than fathers in all categories except nonroutine housework-parents' average enjoyment of housework and childcare tasks did not vary much by gender for most activities. Overall, parents reported relatively high levels of enjoyment of housework and childcare activities, with an average score of 5.3 on a scale of 1 to 7. Parents-and mothers in particular-enjoyed core housework (which includes cooking, cleaning, and clothes care) the least among housework and childcare activities, reporting an average enjoyment score of 4.7 for mothers and 4.9 for fathers. This was followed by nonroutine housework (e.g., grocery shopping, yardwork, 
Table 2: Average parental enjoyment of and time allocation to housework and childcare.

\begin{tabular}{lcccc}
\hline & \multicolumn{2}{c}{ Mothers } & \multicolumn{2}{c}{ Fathers } \\
& Enjoyment & Minutes per day & Enjoyment & Minutes per day \\
\hline Core housework & $4.7^{*}$ & $148^{*}$ & 4.9 & 66 \\
Nonroutine housework & $(1.1)$ & $(85)$ & $(1.1)$ & $(60)$ \\
& 5.1 & 69 & 4.9 & 65 \\
Physical childcare & $(1.1)$ & $(63)$ & $(1.0)$ & $(73)$ \\
& 5.4 & $63^{*}$ & 5.5 & 26 \\
Interactive childcare & $(1.0)$ & $(82)$ & $(1.0)$ & $(41)$ \\
Other childcare & 6.2 & $30^{*}$ & 6.1 & 21 \\
& $(0.8)$ & $(42)$ & $(0.8)$ & $(36)$ \\
$\mathrm{N}$ & 5.3 & $24^{*}$ & 5.4 & 15 \\
& $(1.0)$ & $(32)$ & $(1.0)$ & $(30)$ \\
\hline
\end{tabular}

Note: Numbers in parentheses are standard deviations. ${ }^{*} p<0.05$ : Mothers' characteristics differ significantly from fathers'. 
Table 3: Model 1 results: base model.

\begin{tabular}{|c|c|c|c|}
\hline $\begin{array}{l}\text { Enjoyment } \\
(1=\text { not at all } ; 7=\text { very } \text { much })\end{array}$ & Mothers & Fathers & $\begin{array}{c}\text { Gender } \\
\text { interaction } \\
p \text { value }\end{array}$ \\
\hline \multicolumn{4}{|l|}{ Activity type (ref: core housework) } \\
\hline Nonroutine housework & $\begin{array}{r}0.48^{+} \\
(0.06)\end{array}$ & $\begin{array}{c}0.00 \\
(0.08)\end{array}$ & $<0.01$ \\
\hline Physical childcare & $\begin{array}{r}0.69^{+} \\
(0.05)\end{array}$ & $\begin{array}{r}0.47^{+} \\
(0.07)\end{array}$ & 0.01 \\
\hline Interactive childcare & $\begin{array}{r}1.35^{+} \\
(0.06)\end{array}$ & $\begin{array}{r}1.20^{+} \\
(0.09)\end{array}$ & 0.14 \\
\hline Other childcare & $\begin{array}{r}0.62^{+} \\
(0.07)\end{array}$ & $\begin{array}{r}0.35^{+} \\
(0.09)\end{array}$ & 0.02 \\
\hline \multicolumn{4}{|l|}{ Multitasking (ref: single activity) } \\
\hline Secondary activity is housework & $\begin{array}{l}-0.06 \\
(0.06)\end{array}$ & $\begin{array}{c}0.07 \\
(0.13)\end{array}$ & 0.38 \\
\hline Secondary activity is housework & $\begin{array}{r}0.21^{+} \\
(0.05)\end{array}$ & $\begin{array}{r}0.37^{\dagger} \\
(0.09)\end{array}$ & 0.10 \\
\hline Secondary activity is leisure & $\begin{array}{r}0.22^{\dagger} \\
(0.04)\end{array}$ & $\begin{array}{r}0.19^{\dagger} \\
(0.05)\end{array}$ & 0.60 \\
\hline Secondary activity is other & $\begin{array}{c}0.01 \\
(0.04)\end{array}$ & $\begin{array}{c}0.14 \\
(0.07)\end{array}$ & 0.11 \\
\hline Partner present & $\begin{array}{r}0.15^{\dagger} \\
(0.04)\end{array}$ & $\begin{array}{c}0.06 \\
(0.05)\end{array}$ & 0.15 \\
\hline Constant & $\begin{array}{r}4.46^{+} \\
(0.20)\end{array}$ & $\begin{array}{r}4.30^{\dagger} \\
(0.24)\end{array}$ & $<0.01$ \\
\hline Individual-level variance & 0.77 & 0.73 & 0.75 \\
\hline Episode-level variance & 1.37 & 1.16 & 1.30 \\
\hline Individual-level $\rho$ & 0.36 & 0.39 & 0.37 \\
\hline Number of cases & 25,651 & 10,138 & 35,789 \\
\hline
\end{tabular}

Note: Models control for episode duration, episode duration squared, time of day, daily time spent on paid work, daily time spent on leisure activities, daily time spent on sleep, weekday vs. weekend day, age, age squared, educational attainment, occupational class, partner status, number of children. and whether respondent has a child younger than five years old in the household. Numbers in parentheses are standard errors. ${ }^{*} p<0.05,{ }^{\dagger} p<0.01$.

Meanwhile, fathers enjoyed housework and childcare nearly two-fifths of a point more when multitasking with a secondary childcare task and nearly one-fifth of a point more when multitasking with a secondary leisure activity. Although the results suggest that fathers in particular enjoy housework and childcare time that is multitasked with a second childcare activity, the interaction term between multitasking and gender from our pooled model was not statistically significant.

The results for model 2, assessing whether the association between parents' enjoyment of childcare and housework and partner presence differs by type of activity, are presented in Table 4 . To aid interpretation of the interaction terms, the difference in mothers' and fathers' enjoyment of housework and childcare activities by partner presence is shown graphically in Figure 1. In line with previous research 


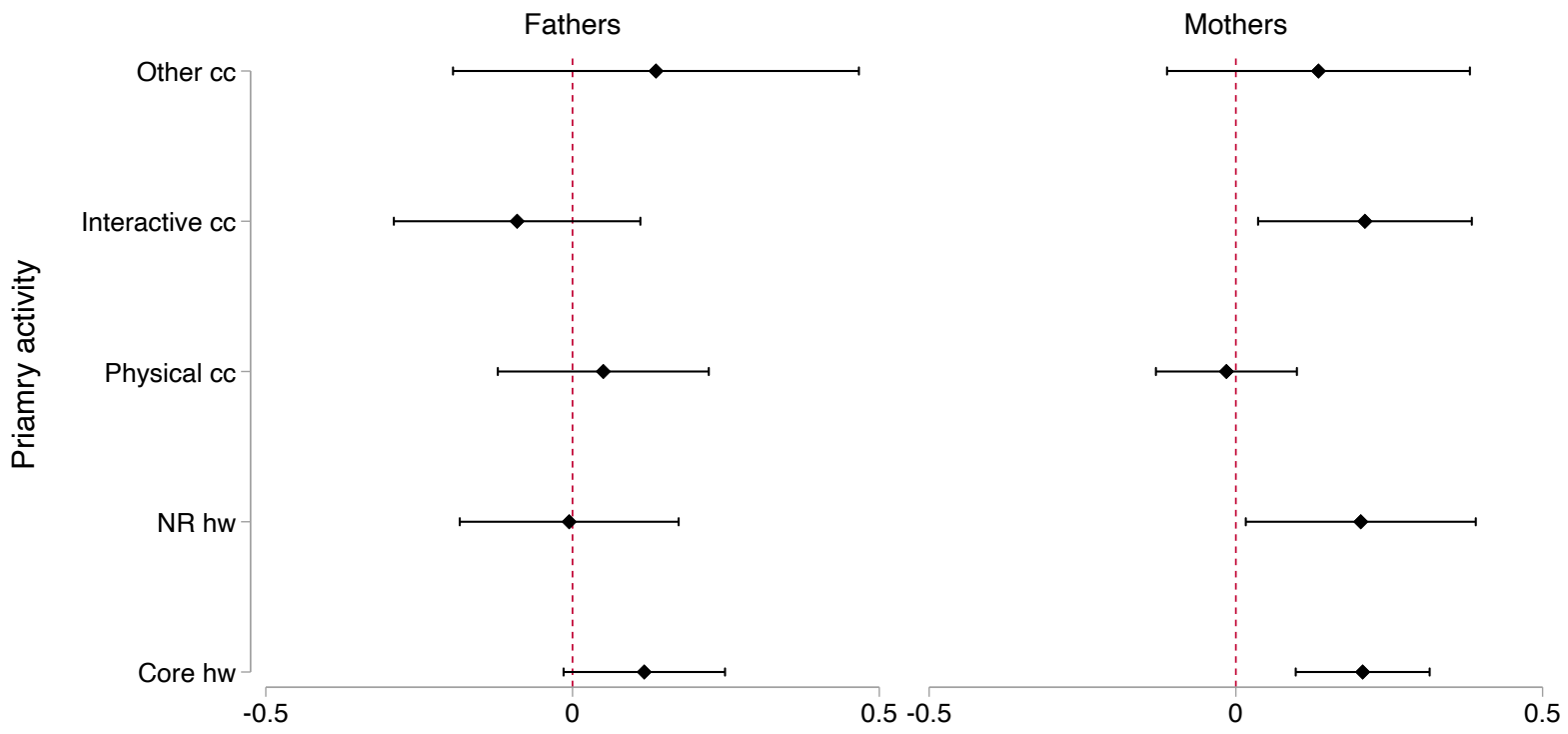

Figure 1: Difference in parents' enjoyment of housework and childcare activities by partner presence. Note: Positive values indicate greater enjoyment of an activity while a partner is present compared with when he or she is not present. Bars indicate 95\% confidence intervals. Abbreviations: cc, childcare; hw, housework; NR, nonroutine.

that suggests that women enjoy traditionally female-typed tasks more when done together with their partners, who are thought to serve in a supporting capacity (Sullivan 1996a, 1996b), mothers reported enjoying core housework around one-fifth of a point more when a partner was present compared with core housework done without a partner around. However, mothers also reported greater enjoyment of nonroutine housework (which encompasses typically male-typed housework such as yardwork or gender-neutral tasks such as household management and food shopping) by around one-fifth of a point. Fathers' enjoyment of housework tasks did not vary statistically significantly by partner presence.

For childcare, mothers reported enjoying interactive childcare around one-fifth of a point more when a partner was present than without a partner, but the same was not the case for fathers. Meanwhile, neither mothers' nor fathers' enjoyment of physical childcare and supervisory childcare differed statistically significantly by partner presence. These results suggest that although the relationship between partner co-presence and enjoyment does vary by the type of task being carried out, the mechanism through which this association operates may not necessarily be through which parent is primarily responsible for the task, as suggested in prior research (e.g., Sullivan 1996a, 1996b).

Given that mothers in our sample were more likely than fathers to be single (as discussed above in reference to Table 1) and single parents are substantially less likely to report spending time in the presence of a partner, we tested whether our results differed when we excluded single parents from our analysis. If the 
Table 4: Model 2 results: partner presence $\times$ activity type interactions.

\begin{tabular}{|c|c|c|c|}
\hline $\begin{array}{l}\text { Enjoyment } \\
(1=\text { not at all } ; 7=\text { very much })\end{array}$ & Mothers & Fathers & $\begin{array}{c}\text { Gender } \\
\text { interaction } \\
p \text { value }\end{array}$ \\
\hline \multicolumn{4}{|l|}{ Activity type (ref: core housework) } \\
\hline Nonroutine housework & $\begin{array}{r}0.48^{+} \\
(0.07)\end{array}$ & $\begin{array}{c}0.05 \\
(0.09)\end{array}$ & $<0.01$ \\
\hline Physical childcare & $\begin{array}{r}0.76^{+} \\
(0.05)\end{array}$ & $\begin{array}{r}0.50^{+} \\
(0.08)\end{array}$ & $<0.01$ \\
\hline Interactive childcare & $\begin{array}{r}1.35^{\dagger} \\
(0.06)\end{array}$ & $\begin{array}{r}1.31^{\dagger} \\
(0.11)\end{array}$ & 0.73 \\
\hline Other childcare & $\begin{array}{r}0.64^{+} \\
(0.08)\end{array}$ & $\begin{array}{r}0.36^{+} \\
(0.10)\end{array}$ & 0.04 \\
\hline Partner present & $\begin{array}{r}0.21^{+} \\
(0.06)\end{array}$ & $\begin{array}{c}0.12 \\
(0.07)\end{array}$ & 0.30 \\
\hline \multicolumn{4}{|l|}{ Activity type $\times$ partner present } \\
\hline Nonroutine housework $\times$ partner present & $\begin{array}{l}0 \\
(0.10)\end{array}$ & $\begin{array}{c}-0.12 \\
(0.10)\end{array}$ & 0.40 \\
\hline Physical childcare $\times$ partner present & $\begin{array}{r}-0.22^{+} \\
(0.08)\end{array}$ & $\begin{array}{c}-0.07 \\
(0.11)\end{array}$ & 0.25 \\
\hline Interactive childcare $\times$ partner present & $\begin{array}{l}0 \\
(0.10)\end{array}$ & $\begin{array}{c}-0.21 \\
(0.13)\end{array}$ & 0.19 \\
\hline Other childcare $\times$ partner present & $\begin{array}{r}-0.07 \\
(0.13)\end{array}$ & $\begin{array}{c}0.02 \\
(0.18)\end{array}$ & 0.68 \\
\hline Constant & $\begin{array}{r}4.44^{+} \\
(0.20)\end{array}$ & $\begin{array}{r}4.28^{+} \\
(0.24)\end{array}$ & $<0.01$ \\
\hline Individual-level variance & 0.77 & 0.73 & 0.75 \\
\hline Episode-level variance & 1.37 & 1.16 & 1.30 \\
\hline Individual-level $\rho$ & 0.36 & 0.39 & 0.37 \\
\hline Number of cases & 25,651 & 10,138 & 35,789 \\
\hline
\end{tabular}

Note: Models control for multitasking, episode duration, episode duration squared, time of day, daily time spent on paid work, daily time spent on leisure activities, daily time spent on sleep, weekday vs. weekend day, age, age squared, educational attainment, occupational class, partner status, number of children, and whether respondent has a child younger than five years old in the household. Numbers in parentheses are standard errors. ${ }^{*} p<0.05,{ }^{\dagger} p<0.01$.

association between episode partner presence and parental enjoyment among partnered parents differed from our main results, we would be concerned that our main results reflect the association between partner status and enjoyment rather than episode-level partner presence itself. However, the results of this robustness analysis, presented in Supplementary Table 2 and Supplementary Figure 1 in the online supplement, are virtually identical in magnitude and statistical significance to our main results, providing reassurance that the associations identified pertain to partner presence during an activity itself rather than parents' partner status.

Table 5 shows the results for model 3 interacting our multitasking indicator with activity type. Again, to ease interpretation of the interaction terms, the key results from model 3 are presented in Figure 2. Our model 1 results suggested that 
multitasking did not appear to detract from parents' enjoyment of housework and childcare activities and that in some cases-for instance, where secondary activities were leisure or childcare activities-parents reported enjoying time more while multitasking than while carrying out a singular task. The results from model 3 indicate that the association between multitasking and parents' enjoyment does vary by which types of primary and secondary tasks are paired together.

We found that combining primary housework tasks with leisure activities was associated with greater enjoyment compared with housework tasks that were carried out as sole activities. But surprisingly, so was combining primary housework tasks with childcare and even other housework tasks at times. Mothers enjoyed primary core housework nearly 0.4 points more when multitasking with another housework task and 0.3 points more when multitasking either with a secondary childcare task or a leisure task relative to core housework that was single-tasked. Similarly, fathers enjoyed core housework around one-half of a point more when multitasking with another housework or childcare task and nearly 0.3 points more when multitasking with a leisure task. For primary nonroutine housework, only multitasking with a leisure activity was significantly and meaningfully more enjoyable than single-tasking nonroutine housework among mothers, who enjoyed the task 0.2 points more when combining it with a leisure task. Fathers also enjoyed nonroutine housework around a quarter of a point more when combining it with a leisure activity and nearly one full point more when combining it with a secondary childcare task.

When it came to primary childcare tasks, mothers enjoyed most types of childcare more when they were combined with a leisure activity. Mothers enjoyed physical childcare time around a quarter of a point more and enjoyed interactive childcare time around 0.3 points more when combining these activities with leisure rather than carrying these tasks out as single activities. The same pattern was true for fathers, although the magnitudes of associations were smaller and not statistically significant. Contrary to possible assumptions that carrying out multiple childcare activities at the same time might be indicative of role overload, mothers enjoyed physical childcare tasks one-fifth of a point more when combining these activities with secondary childcare tasks. However, they enjoyed interactive childcare one-fifth of a point less when combining it with secondary housework tasks. Fathers, by contrast, reported enjoying other childcare activities (which include supervisory childcare and child-related travel) more than a full point more when combining these tasks with a secondary housework task than when single-tasking.

Taken together, these results indicate both similarities and differences in the association between multitasking and parental enjoyment by gender. Both mothers' and fathers' primary housework time was improved by nearly any type of multitasking when compared with single-tasked housework. However, for mothers, adding housework as a secondary activity to primary childcare tasks was associated with lower enjoyment in most instances, whereas this did not appear to be the case for fathers, who actually reported greater enjoyment of some childcare tasks when a secondary housework task was carried out alongside it. 
Table 5: Model 3 results: multitasking $\times$ activity type interactions.

\begin{tabular}{|c|c|c|c|}
\hline $\begin{array}{l}\text { Enjoyment } \\
(1=\text { not at all; } 7=\text { very } \text { much })\end{array}$ & Mothers & Fathers & $\begin{array}{c}\text { Gender } \\
\text { interaction } \\
p \text { value }\end{array}$ \\
\hline \multicolumn{4}{|l|}{ Activity type (ref: core housework) } \\
\hline Nonroutine housework & $\begin{array}{r}0.49^{\dagger} \\
(0.08)\end{array}$ & $\begin{array}{c}0.00 \\
(0.08)\end{array}$ & $<0.01$ \\
\hline Physical childcare & $\begin{array}{r}0.70^{+} \\
(0.05)\end{array}$ & $\begin{array}{r}0.51^{+} \\
(0.08)\end{array}$ & 0.04 \\
\hline Interactive childcare & $\begin{array}{r}1.40^{\dagger} \\
(0.06)\end{array}$ & $\begin{array}{r}1.27^{+} \\
(0.10)\end{array}$ & 0.25 \\
\hline Other childcare & $\begin{array}{r}0.69^{+} \\
(0.09)\end{array}$ & $\begin{array}{r}0.44^{+} \\
(0.10)\end{array}$ & 0.05 \\
\hline \multicolumn{4}{|l|}{ Multitasking (ref: single activity) } \\
\hline Secondary activity is housework & $\begin{array}{r}0.39^{\dagger} \\
(0.14)\end{array}$ & $\begin{array}{r}0.55^{*} \\
(0.25)\end{array}$ & 0.59 \\
\hline Secondary activity is childcare & $\begin{array}{r}0.33^{+} \\
(0.07)\end{array}$ & $\begin{array}{r}0.54^{+} \\
(0.10)\end{array}$ & 0.10 \\
\hline Secondary activity is leisure & $\begin{array}{r}0.26^{+} \\
(0.06)\end{array}$ & $\begin{array}{r}0.25^{+} \\
(0.09)\end{array}$ & 0.93 \\
\hline Secondary activity is other & $\begin{array}{c}-0.02 \\
(0.05)\end{array}$ & $\begin{array}{c}0.10 \\
(0.08)\end{array}$ & 0.23 \\
\hline \multicolumn{4}{|l|}{ Activity type $\times$ multitasking } \\
\hline Nonroutine housework $\times$ secondary housework & $\begin{array}{c}-0.39 \\
(0.28)\end{array}$ & $\begin{array}{l}-0.61 \\
(0.47)\end{array}$ & 0.68 \\
\hline Nonroutine housework $\times$ secondary childcare & $\begin{array}{c}-0.21 \\
(0.18)\end{array}$ & $\begin{array}{c}0.41 \\
(0.28)\end{array}$ & 0.06 \\
\hline Nonroutine housework $\times$ secondary leisure & $\begin{array}{c}-0.06 \\
(0.10)\end{array}$ & $\begin{array}{c}0.01 \\
(0.14)\end{array}$ & 0.68 \\
\hline Nonroutine housework $\times$ secondary other & $\begin{array}{c}0.14 \\
(0.12)\end{array}$ & $\begin{array}{c}0.17 \\
(0.15)\end{array}$ & 0.87 \\
\hline Physical childcare $\times$ secondary housework & $\begin{array}{r}-0.60^{\dagger} \\
(0.20)\end{array}$ & $\begin{array}{r}-0.77^{*} \\
(0.36)\end{array}$ & 0.68 \\
\hline Physical childcare $\times$ secondary childcare & $\begin{array}{c}-0.12 \\
(0.10)\end{array}$ & $\begin{array}{l}-0.29 \\
(0.22)\end{array}$ & 0.50 \\
\hline Physical childcare $\times$ secondary leisure & $\begin{array}{c}-0.02 \\
(0.09)\end{array}$ & $\begin{array}{c}-0.13 \\
(0.17)\end{array}$ & 0.58 \\
\hline Physical childcare $\times$ secondary other & $\begin{array}{c}0.22 \\
(0.13)\end{array}$ & $\begin{array}{c}0.15 \\
(0.16)\end{array}$ & 0.74 \\
\hline Interactive childcare $\times$ secondary housework & $\begin{array}{r}-0.60^{+} \\
(0.17)\end{array}$ & $\begin{array}{c}-0.47 \\
(0.39)\end{array}$ & 0.76 \\
\hline Interactive childcare $\times$ secondary childcare & $\begin{array}{r}-0.47^{+} \\
(0.12)\end{array}$ & $\begin{array}{r}-0.54^{+} \\
(0.16)\end{array}$ & 0.73 \\
\hline Interactive childcare $\times$ secondary leisure & $\begin{array}{c}0.02 \\
(0.12)\end{array}$ & $\begin{array}{c}-0.21 \\
(0.12)\end{array}$ & 0.17 \\
\hline Interactive childcare $\times$ secondary other & $\begin{array}{c}0.11 \\
(0.17)\end{array}$ & $\begin{array}{c}0.00 \\
(0.25)\end{array}$ & 0.70 \\
\hline
\end{tabular}


Table 5 continued

\begin{tabular}{|c|c|c|c|}
\hline $\begin{array}{l}\text { Enjoyment } \\
(1=\text { not at all; } 7 \text { = very much })\end{array}$ & Mothers & Fathers & $\begin{array}{c}\text { Gender } \\
\text { interaction } \\
p \text { value }\end{array}$ \\
\hline Other childcare $\times$ secondary housework & $\begin{array}{r}-0.57^{*} \\
(0.22)\end{array}$ & $\begin{array}{r}0.51^{*} \\
(0.24)\end{array}$ & $<0.01$ \\
\hline Other childcare $\times$ secondary childcare & $\begin{array}{c}-0.15 \\
(0.16)\end{array}$ & $\begin{array}{r}-0.35^{*} \\
(0.17)\end{array}$ & 0.41 \\
\hline Other childcare $\times$ secondary leisure & $\begin{array}{r}-0.35^{\dagger} \\
(0.13)\end{array}$ & $\begin{array}{c}-0.27 \\
(0.14)\end{array}$ & 0.69 \\
\hline Other childcare $\times$ secondary other & $\begin{array}{c}0.17 \\
(0.31)\end{array}$ & $\begin{array}{r}0.12) \\
(0.21)\end{array}$ & 0.90 \\
\hline Constant & $\begin{array}{r}4.43^{\dagger} \\
(0.20)\end{array}$ & $\begin{array}{r}4.27^{+} \\
(0.24)\end{array}$ & $<0.01$ \\
\hline Individual-level variance & 0.77 & 0.73 & 0.75 \\
\hline Episode-level variance & 1.37 & 1.15 & 1.29 \\
\hline Individual-level $\rho$ & 0.36 & 0.39 & 0.37 \\
\hline Number of cases & 25,651 & 10,138 & 35,789 \\
\hline
\end{tabular}

Note: Models control for partner presence, episode duration, episode duration squared, time of day, daily time spent on paid work, daily time spent on leisure activities, daily time spent on sleep, weekday vs. weekend day, age, age squared, educational attainment, occupational class, partner status, number of children, and whether respondent has a child younger than five years old in the household. Numbers in parentheses are standard errors. ${ }^{*} p<0.05,{ }^{+} p<0.01$.

\section{Discussion}

This article re-evaluates the relationship between parents' enjoyment of housework and childcare time and two contextual characteristics of time use that have garnered particular attention in the literature: partner co-presence and multitasking. Using time diary data from the United Kingdom and an empirical strategy particularly suited to the task, we test whether the associations between partner presence, multitasking, and subjective well-being differ across the types of housework and childcare being carried out, with attention to heterogeneity by gender.

Our results for partner co-presence suggest that although partner presence is associated with greater enjoyment of childcare and housework time, this association was only statistically and meaningfully significant for mothers and did not apply to all types of housework and childcare. Partner presence was associated with mothers' greater enjoyment of core housework, nonroutine housework, and interactive childcare but not physical childcare or other childcare. By contrast, variation in fathers' enjoyment of housework and childcare tasks by partner co-presence was smaller and not statistically significant.

Although prior research has suggested that mothers' enjoyment of female-typed tasks is improved when (perhaps at women's prompting) men "help out" with these tasks (Sullivan 1996a; 1996b), this hypothesis was not entirely supported by our results. Although mothers reported greater enjoyment of core housework with a partner present, this was also true of more gender-neutral nonroutine housework 


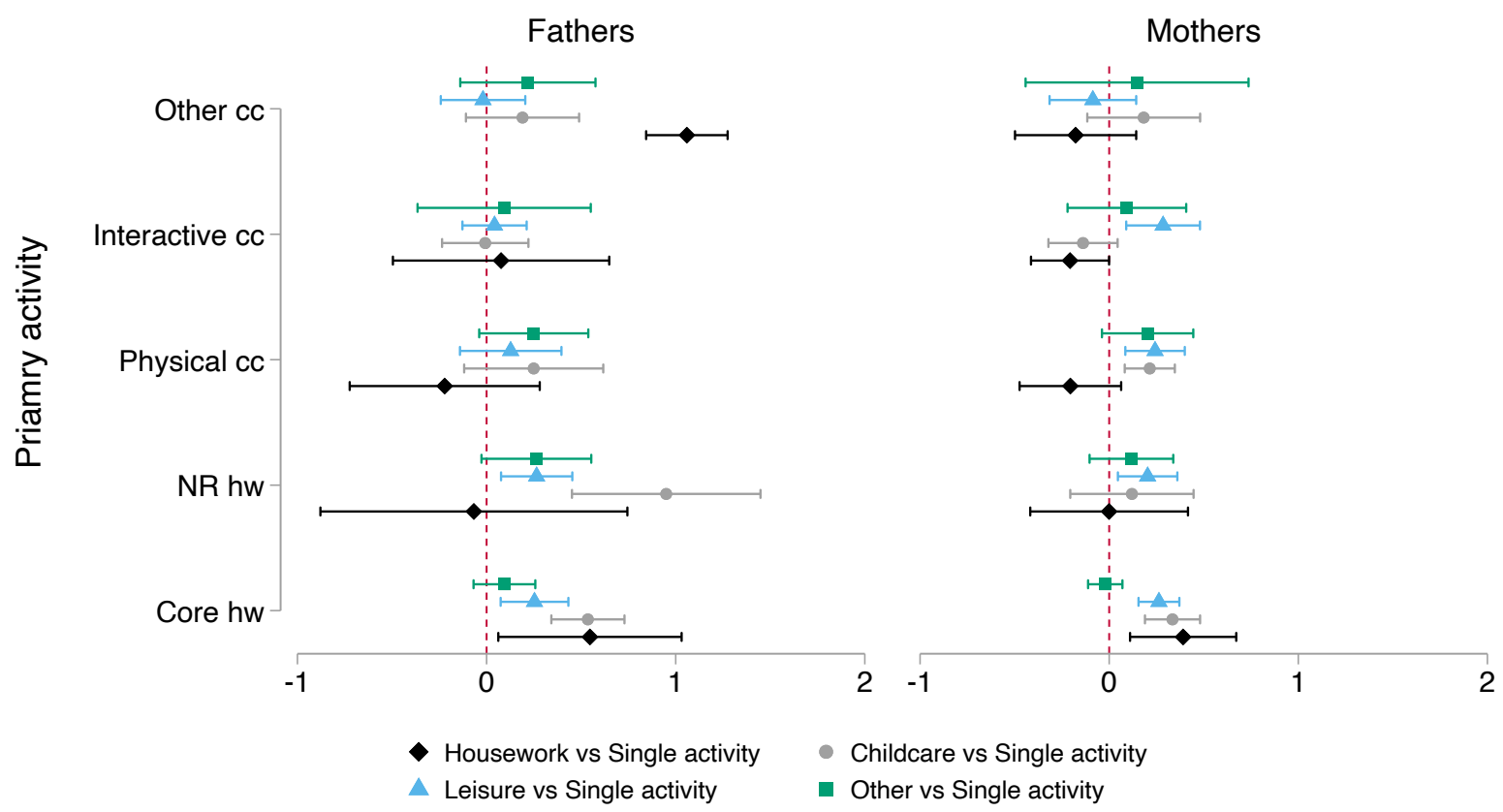

Figure 2: Difference in parents' enjoyment of housework and childcare activities by multitasking. Note: Color-coded point estimates (and their respective 95\% confidence intervals) show the difference in parents' enjoyment when an activity is multitasked vs. single-tasked, disaggregated by secondary activity type. Positive values indicate greater enjoyment of an activity while multitasking compared with single-tasking. Abbreviations: cc, childcare; hw, housework; NR, nonroutine.

tasks. Meanwhile, neither mothers nor fathers enjoyed traditionally female-typed childcare activities like physical childcare more with a partner present. It is possible, however, that our conceptualization of female-typed tasks, which is based on the amount of time men and women tend to devote to carrying out these tasks, fails to take into account the extent to which women "project manage" even the tasks they don't ultimately carry out. Recent qualitative evidence on the cognitive division of household labor suggests that even for tasks that are ultimately carried out by male partners, women often take responsibility for anticipating and identifying the work that needs to be done and monitoring its completion (Daminger 2019). In this way, the mechanism through which partner presence is hypothesized to affect enjoyment may be correct, but our conceptualization of what tasks are likely to be mothers' responsibility may be insufficient.

Alternatively, there may be multiple mechanisms through which partner presence relates to parents' well-being. For instance, one might theorize that mothers enjoy interactive childcare more when a partner is present during that activity not because fathers' help relieves some of the mothers' responsibility but because fathers' presence promotes family bonding. However, why this positive association for interactive childcare does not appear to extend to fathers (in contrast with U.S. evidence from Roeters and Gracia [2016]) remains an important question. Further 
research is needed to understand the mechanism through which partner presence improves mothers' enjoyment of some housework and childcare tasks but not others and why this pattern is not observed among fathers. One potentially fruitful course of study would be to examine the association between partner presence and enjoyment while partners are carrying out the same activity versus when partners are merely sharing the same space. Recent research suggests that important gender imbalances exist in what partners do when they are together, with men more likely to engage in leisure activities and women more likely to do domestic chores (Vagni 2019). Couple-level analysis distinguishing between partner co-presence during an activity and partner co-production of that activity could provide further insight into the relationship between partners' time together and parental well-being.

For multitasking, our results suggest that parents' experience of multitasking does indeed vary depending on the tasks being carried out, a pattern that has largely been ignored in empirical literature testing whether multitasking in general is associated with negative affect (e.g., Offer and Schneider 2011). We investigated whether combining two unpaid work tasks is associated with lower enjoyment and whether combining an unpaid work task with a secondary leisure activity is associated with greater enjoyment. However, our results suggest the relationship between multitasking, activity type, and enjoyment is not so straightforward. We found that parents-and especially mothers-tended to enjoy housework and childcare tasks more when combining these activities with a secondary leisure activity than they did when carrying activities out as single tasks. But when it came to combining multiple unpaid work tasks, in some instances this was associated with lower enjoyment, whereas in others it was associated with greater enjoyment. For both mothers and fathers, nearly any type of multitasking was associated with greater enjoyment of primary housework-even pairing these activities with a second housework task. By contrast, mothers reported lower enjoyment of interactive childcare when combining interactive childcare with a housework task but reported greater enjoyment of physical childcare time while carrying out two childcare tasks at the same time.

These results demonstrate a heterogeneity in parents' experiences of multitasked episodes that has often been overlooked. Whereas prior research has often framed multitasking as an indicator of overwork and time scarcity (Bianchi et al. 2006; Offer and Schneider 2011) or simply as an indicator of the compatibility of housework and childcare activities and a product of total time spent at home (Sullivan and Gershuny 2013, 2018), we offer a different conceptualization. Our results suggest that in reality individuals may multitask for a variety of reasons, with different implications for their well-being. In some cases, multitasking may be a way parents try to fulfil multiple responsibilities in a short period of time, whereas in other cases they may multitask an unpleasant or repetitive task with a more pleasant one to increase their overall enjoyment. Our analysis of multitasking by activity type provides a starting point in distinguishing between these different types of multitasking, but further analysis could establish in greater detail what types of multitasking episodes are detrimental to parents' well-being and which are not by assessing further heterogeneity by time of day, location, or multitasking in the presence of other family members. 
There are likely many other factors that are important in shaping parents' wellbeing that are not assessed in this research. These include the demands of paid work (including job quality, availability of paid time off and flexible work options, and experience of work-family conflict), caring responsibilities for older family members, the quality of relationships among the parents and between parents and their children, access to childcare (including affordability of formal childcare options and access to informal sources of childcare support from grandparents or other family members), and access to wider community support networks. Whether and how these factors relate to how parents experience their childcare and housework responsibilities may provide greater insight into how parental well-being may be improved and should be explored in future research.

Despite these limitations, the results from this analysis add nuance to existing literature on how the contextual characteristics of time use relate to parents' subjective well-being during housework and childcare time. For instance, although it is well established that core housework is among the least enjoyed activities that individuals—and particularly women—carry out (Gershuny 2013; Gershuny and Sullivan 2019), we find that even this disliked task is experienced as more enjoyable when multitasking and, for mothers, when in the presence of a partner. Thus, although parents may have limited control over whether to carry out the childcare and housework required to sustain family life, this analysis suggests that changes in the context in which these responsibilities are carried out may improve or worsen parents' experience of their parenting responsibilities.

\section{Notes}

1 Although some research analyzes parents' experience of all activities carried out in the presence of a child, regardless of whether it was identified as a childcare activity or not (e.g., Musick et al. 2016), in UKTUS, it is only possible to identify tasks carried out in the presence of children aged 0 to 7 . We therefore focus our analysis on activities identified as childcare rather than all activities carried out in the presence of a child.

\section{References}

Bachmann, Olga, Carola Grunschel, and Stefan Fries. 2019. "Multitasking and Feeling Good? Autonomy of Additional Activities Predicts Affect." Journal of Happiness Studies 20(3):899-918. https : //doi.org/10.1007/s10902-018-9973-3

Bianchi, Suzanne M., John P. Robinson, and Melissa A. Milkie. 2006. Changing Rhythms of American Family Life. New York: Russell Sage Foundation.

Connolly, Sara, Matthew Aldrich, Margaret O'Brien, Svetlana Speight, and Eloise Poole. 2016. "Britain's Slow Movement to a Gender Egalitarian Equilibrium: Parents and Employment in the UK 2001-13." Work, Employment and Society 30(5):838-57. https : //doi.org/10.1177/0950017016638009

Craig, Lyn. 2006a. "Children and the Revolution: A Time-Diary Analysis of the Impact of Motherhood on Daily Workload." Journal of Sociology 42(2):125-43. https : //doi .org/10. $1177 / 1440783306064942$ 
Craig, Lyn. 2006b. "Does Father Care Mean Fathers Share? A Comparison of How Mothers and Fathers in Intact Families Spend Time with Children." Gender E Society 20(2):259-81. https://doi.org/10.1177/0891243205285212

Craig, Lyn, and Judith E. Brown. 2017. “Feeling Rushed: Gendered Time Quality, Work Hours, Nonstandard Work Schedules, and Spousal Crossover." Journal of Marriage and Family 79(1):225-42. https : //doi .org/10.1111/jomf . 12320

Daminger, Allison. 2019. "The Cognitive Dimension of Household Labor." American Sociological Review 84(4):609-33. https://doi .org/10.1177/0003122419859007

Dow, Gregory T., and F. Thomas Juster. 1985. "Goods, Time and Well-Being: The Joint Dependence Problem," in Time, Goods, and Well-Being, edited by F. Thomas Juster and Frank P. Stafford. Ann Arbor, MI: University of Michigan Institute for Social Research.

Flood, Sarah M., and Katie R. Genadek. 2016. "Time for Each Other: Work and Family Constraints among Couples." Journal of Marriage and Family 78(1):142-64. https://doi . org/10.1111/jomf. 12255

Gershuny, Jonathan. 2013. "National Utility: Measuring the Enjoyment of Activities." European Sociological Review 29(5):996-1009. https : //doi . org/10.1093/esr/jcs077

Gershuny, J., and O. Sullivan. 2017. United Kingdom Time Use Survey, 2014-2015. Center for Time Use Research, University of Oxford. http://doi .org/10.5255/UKDA-SN-8128-1.

Gershuny, Jonathan, and Oriel Sullivan. 2019. What We Really Do All Day: Insights from the Centre for Time Use Research. London: Penguin Books Limited.

Glass, Jennifer, Robin W. Simon, and Matthew A. Andersson. 2016. "Parenthood and Happiness: Effects of Work-Family Reconciliation Policies in 22 OECD Countries." American Journal of Sociology 122(3):886-929. https : //doi . org/10.1086/688892

Hays, Sharon. 1996. The Cultural Contradictions of Motherhood. New Haven: Yale University Press.

Hill, Martha S. 1988. "Marital Stability and Spouses' Shared Time: A Multidisciplinary Hypothesis." Journal of Family Issues 9(4):427-51. https ://doi .org/10.1177/ 019251388009004001

Kahneman, Daniel, E. Diener, and Norbert Schwarz. 1999. Well-Being: The Foundations of Hedonic Psychology. New York: Russell Sage Foundation.

Kahneman, Daniel, and Alan B. Krueger. 2006. "Developments in the Measurement of Subjective Well-Being." Journal of Economic Perspectives 20(1):3-24. https : //doi .org/10 . $1257 / 089533006776526030$

Lee, Yoonjoo, Sandra L. Hofferth, Sarah M. Flood, and Kimberly Fisher. 2016. "Reliability, Validity, and Variability of the Subjective Well-Being Questions in the 2010 American Time Use Survey." Social Indicators Research 126(3):1355-73. https : //doi .org/10.1007/ s11205-015-0923-8

Luhmann, Maike, Ulrich Schimmack, and Michael Eid. 2011. "Stability and Variability in the Relationship between Subjective Well-Being and Income." Journal of Research in Personality 45(2):186-97. https://doi.org/10.1016/j.jrp.2011.01.004

Mattingly, Marybeth J., and Liana C. Sayer. 2006. “Under Pressure: Gender Differences in the Relationship between Free Time and Feeling Rushed." Journal of Marriage and Family 68(1):205-21. https://doi.org/10.1111/j.1741-3737.2006.00242.x

McDonnell, Cadhla, Nancy Luke, and Susan E. Short. 2019. "Happy Moms, Happier Dads: Gendered Caregiving and Parents' Affect." Journal of Family Issues 40(17):2553-81. https://doi.org/10.1177/0192513X19860179 
Meier, Ann, Kelly Musick, Jocelyn Fischer, and Sarah Flood. 2018. "Mothers' and Fathers' Well-Being in Parenting across the Arch of Child Development." Journal of Marriage and Family 80(4):992-1004. https://doi .org/10.1111/jomf .12491

Musick, Kelly, Ann Meier, and Sarah Flood. 2016. "How Parents Fare: Mothers' and Fathers' Subjective Well-Being in Time with Children." American Sociological Review 81(5):1069-95. https://doi.org/10.1177/0003122416663917

Nomaguchi, Kei, and Melissa A. Milkie. 2017. "Sociological Perspectives on Parenting Stress: How Social Structure and Culture Shape Parental Strain and the Well-Being of Parents and Children." Pp. 47-73 in Parental Stress and Early Child Development, edited by K. Deater-Deckard and R. Panneton. Cham: Springer. https://doi .org/10.1007/ 978-3-319-55376-4_3

O’Brien, Margaret, Sara Connolly, Svetlana Speight, Matthew Aldrich, and Eloise Poole. 2015. "Father Involvement with Young Children in the Contemporary United Kingdom." in Father Involvement in Early Years, edited by M. Alder and K. Lenz. Bristol: Policy Press. https://doi.org/10.1332/policypress/9781447318996.003.0005

Offer, Shira. 2014. "Time with Children and Employed Parents' Emotional Well-Being." Social Science Research 47:92-203. https: //doi .org/10.1016/j .ssresearch.2014.05.003

Offer, Shira, and Barbara Schneider. 2011. "Revisiting the Gender Gap in Time-Use Patterns: Multitasking and Well-Being among Mothers and Fathers in Dual-Earner Families." American Sociological Review 76(6):809-33. https://doi.org/10.1177/0003122411425170

Office for National Statistics. 2018. Families and the Labour Market, England: 2018. London.

Pearlin, Leonard I. 1989. "The Sociological Study of Stress." Journal of Health and Social Behavior 30(3):241-56. https : //doi . org/10.2307/2136956

Pearlin, Leonard I. 1999. “The Stress Process Revisited." Pp. 395-415 in Handbook of the Sociology of Mental Health, edited by Carol S. Aneshensel and Jo C. Phelan. New York: Kluwer Academic/Plenum Publishers. https : //doi .org/10.1007/0-387-36223-1_19

Raley, Sara, Suzanne M. Bianchi, and Wendy Wang. 2012. “When Do Fathers Care? Mothers' Economic Contribution and Fathers' Involvement in Child Care." American Journal of Sociology 117(5):1422-59. https : //doi .org/10.1086/663354

Robinson, John. 2013. As We Like (Still) Like It: Socializing, Religion, Kids Remain Our Favorite Daily Activities. PWP-MPRC-2014-001.

Roeters, Anne, and Pablo Gracia. 2016. "Child Care Time, Parents' Well-Being, and Gender: Evidence from the American Time Use Survey." Journal of Child and Family Studies 25(8):2469-79. https://doi.org/10.1007/s10826-016-0416-7

Roeters, Anne, and Judith K. Treas. 2011. "Parental Work Demands and Parent-Child, Family, and Couple Leisure in Dutch Families: What Gives?" Journal of Family Issues 32(3):269-91.https://doi .org/10.1177/0192513X10379204

Sayer, Liana. 2007. "More Work for Mothers? Trends and Gender Differences in Multitasking." Pp. 41-55 in Competing Claims in Work and Family Life, edited by Tanja van der Lippe and Pascale Peters. Cheltenham: Edward Elgar.

Sayer, Liana C., Suzanne M. Bianchi, and John P. Robinson. 2004. “Are Parents Investing Less in Children? Trends in Mothers' and Fathers' Time with Children." American Journal of Sociology 110(1):1-43. https: //doi .org/10.1086/386270

Stone, Arthur A., and Christopher Mackie, eds. 2013. Subjective Well-Being: Measuring Happiness, Suffering, and Other Dimensions of Experience. Washington, DC: The National Academies Press. 
Sullivan, Oriel. 1996a. "The Enjoyment of Activities: Do Couples Affect Each Others' WellBeing? Measuring Well-Being: The Enjoyment of Activities within Couples." Social Indicators Research 38(1):81-102. https : //doi .org/10.1007/BF00293787

Sullivan, Oriel. 1996b. "Time Co-ordination, the Domestic Division of Labour and Affective Relations: Time Use and the Enjoyment of Activities within Couples." Sociology 30(1):79100. https://doi.org/10.1177/0038038596030001006

Sullivan, Oriel. 1997. "Time Waits for No (Wo)Man: An Investigation of the Gendered Experience of Domestic Time." Sociology 31(2):221-39. https://doi.org/10.1177/ 0038038597031002003

Sullivan, Oriel, and Jonathan Gershuny. 2013. “Domestic Outsourcing and Multitasking: How Much Do They Really Contribute?" Social Science Research 42(5):1311-24. https : //doi.org/10.1016/j.ssresearch.2013.05.004

Sullivan, Oriel, and Jonathan Gershuny. 2018. "Speed-up Society? Evidence from the UK 2000 and 2015 Time Use Diary Surveys." Sociology 52(1):20-38. https ://doi .org/10. $1177 / 0038038517712914$

Vagni, Giacomo. 2019. "Alone Together: Gender Inequalities in Couple Time." Social Indicators Research 146(3):487-509. https: //doi .org/10.1007/s11205-019-02135-7

White, Lynn K. 1983. “Determinants of Spousal Interaction: Marital Structure or Marital Happiness." Journal of Marriage and the Family 45(3):511-9. https : //doi .org/10. 2307/ 351656

Zuo, Jiping. 1992. “The Reciprocal Relationship between Marital Interaction and Marital Happiness: A Three-Wave Study." Journal of Marriage and the Family 54(4):870-8. https : //doi.org/10.2307/353168

Acknowledgments: This research was funded by a grant from the Economic and Social Research Council's Secondary Data Analysis Initiative ES/R004854/1. We are grateful to Professor Oriel Sullivan for her comments on previous versions of this manuscript, which have greatly improved the article. We would also like to thank Robert Wishart, who provided analytical advice and expertise. Finally, we thank members of the project Advisory Group for their input and support throughout the project.

Allison Dunatchik: The University of Pennsylvania, Department of Sociology. E-mail: adunat@sas.upenn.edu.

Svetlana Speight: The National Centre for Social Research. E-mail: svetlana.speight@natcen.ac.uk. 